\title{
Chemical Ablation
}

National Cancer Institute

\section{Source}

National Cancer Institute. Chemical Ablation. NCI Thesaurus. Code C111157.

Removal, separation, detachment, extirpation, or eradication of a body part, pathway, or function by chemical means. 